\title{
Livro: círculo da imensidade
}

\section{Book: circle of immensity}

DAISY TURRER

Universidade Federal de Minas Gerais (UFMG) Brasil

\section{RESUMO}

Este ensaio apresenta a articulação estabelecida entre duas pesquisas: a de artista e professora de gravura e as de mestrado e de doutorado. A primeira é dedicada às provas de estado, às leituras dos acasos e dos sentidos, do que foi subtraído e ou acrescido (do que se perde e do que se ganha) à imagem impressa mediada pela matriz que a conduziu. A segunda, de maneira análoga, toma o livro impresso como uma matriz que reproduz a escrita e que, mediada por ele, poderá estar também subtraída e ou acrescida de algo. A hipótese de João Guimarães Rosa de que "o livro pode valer pelo muito que nele não deveu caber", presente no final do prefácio Aletria e Hermenêutica, do livro Tutaméia: terceiras estórias, perpassa ambas as pesquisas indo se encontrar na Biblioteca Para-Luz, obra que, com seus livros vazios, desamarrados e empilhados, abriga e desabriga as imagens do vazio do mundo no mundo do livro.

\section{PALAVRAS - CHAVE}

Imagem, letra, livro.

\begin{abstract}
A B S T R A C T
This essay presents the articulation established between two researches: one of an artist and professor of printmaking and the other of my masters and doctorate. The first is dedicated to the proofs of state, to the interpretation of chance and senses, of what has been substracted and or added lof what is lost and what is gained) to the printed image mediated by the matrix that had led it. The second, in an analogous way, takes the printed book as a matrix that reproduces writting and which, mediated by it, may also have something that is subtracted or added to it. The hypothesis of João Guimarães Rosa that "the book might be worth as much as what did not fit in it", presented at the end of the preface Aletria and Hermeneutics, from the book Tutaméia: third stories, runs through both researches and meets at Para-Luz Library, a work that, with its empty books, untied and stacked, shelters and unshelters images of the emptiness of the world in the world of the book.
\end{abstract}

\section{KEYWORDS}

Image, letter, book. 
Para escrever é preciso que já se escreva.

Maurice Blanchot

Agora, juntos vamos fazer um certo livro - Tudo nem estava concluído, nunca, êrro, recomêço, rêerro.

João Guimarães Rosa

O livro pode valer pelo que muito que nele não deveu caber.

João Guimarães Rosa

Essas frases da epígrafe me acompanham e falar sobre livro, em minha pesquisa como artista, significa falar de um certo livro, envolve falar da "Biblioteca Para-luz" e seus desdobramentos, articulados às minhas experiências no campo da gravura, assim como nas minhas pesquisas de mestrado e doutorado.

João Guimarães Rosa escreve, ao final do prefácio “Aletria e Hermenêutica”, que "o livro pode valer pelo muito que nele não deveu caber". Se no início de um livro o prefácio nos incita a adentrá-lo, Rosa, ao contrário, nos lança, de antemão, para fora do livro e alerta ao leitor que aquilo que será lido é apenas o que ficou abrigado em letra de forma impressa.

A própria hipótese do autor sintetiza o percurso de meus estudos, abrindo, ela mesma, os dois campos distintos que envolvem o livro como abrigo da escrita - realidade de papel e impressão que circunscreve e veicula a palavra escrita - e o livro imaterial incircunscrito que, ao contrário, é desabrigo da escrita, a nascente de todos os livros.

No mestrado, "O livro e a ausência de Livro em Tutaméia de Guimarães Rosa (2001)"1, trabalhei os textos de "Tutaméia: terceiras estórias" (1985) em sua disseminação, contornando as suas margens - os prefácios, o itinerário da obra, a pré-publicação de seus textos em revistas e jornais como um ensaio de livro - antes de se tornar uma publicação organizada pelo autor, que reuniu os textos dispersos para a primeira edição em 1967.

No doutorado, "Dos estados do livro (2005)"2, ainda instigada pela hipótese de Rosa, fui para o fora do livro, pelo o que ele pode valer, na tentativa de me aproximar desse fora que nos devolve a ausência como presença, mas também a presença ausente do que nele não coube, e que nele permanece a escrever para além da mancha tipográfica impressa.

O título escolhido da tese faz referência direta ao meu trabalho, às experiências na lida com a arte de imprimir e de gravar. Durante a gravação de uma matriz, o artista faz várias provas de estado antes de se decidir por uma tiragem, uma edição. São imagens indecisas, preciosas, que podem valer pelo muito que nelas se excluiu no processo de gravação e impressão. Nelas permanecem latentes as linhas e manchas apagadas e regravadas que, embora veladas, mostram,

1 Título da dissertação defendida em 2001, em Estudos Literários, pelo Programa de Pós Graduação da Faculdade de Letras da Universidade Federal de Minas Gerais (UFMG), posteriormente publicado pela editora Autêntica, em 2002.

2 Título da tese de defendida em 2005, em Literatura Comparada, no Programa de Pós Graduação da Faculdade de Letras da Universidade Federal de Minas Gerais (UFMG). 
ainda assim, o que poderia ter sido ou o que poderia vir a ser a imagem impressa. Da mesma forma, na lida do escritor diante da experiência da escrita, em meio a rascunhos e manuscritos, permanecem provas de estado de um livro que, uma vez impresso, carrega também o que poderia ter sido ou o que poderia vir a ser.

A gravura acontece por uma série de procedimentos, e, por isso, gosto de pensá-la como um fenômeno condutor de imagens. $O$ que me fascina - tanto que fiz dela meu campo de pesquisas em arte - são as marcas do deslocamento que ela carrega em suas passagens do desenho para a matriz, quer seja tirando o risco com carbono, quer seja por uma incisão direta, e depois da matriz para o papel impresso. Nesse caminho, a materialidade do suporte torna-se amalgamada à imagem, dando-nos a ver não mais o desenho, mas sua imagem mediada pela matriz, não mais a leitura do gesto escorregadio do lápis, mas a leitura dos sulcos e texturas das goivas a se arriscarem no indelével. Do mesmo modo podemos pensar: não mais a escrita, mas a escrita mediada pelo livro, matriz que a reproduz.

E tudo o que conduz perde ou ganha ao migrar de um lugar para o outro, fazendo com que a gravura seja uma imagem sempre subtraída e acrescida de algo. Assim, o gravador torna-se um leitor às avessas, a buscar o que se perdeu desviando-se. E o que se ganhou nessas passagens são ranhuras que, quase imperceptíveis na matriz, insistem em aparecer, em permanecer na imagem impressa. O livro como abrigo da escrita, como matriz que a conduz e por ela é mediado, torna-se também um lugar de passagem e estará sempre subtraído (e) ou acrescido de algo.

No entanto, mesmo sabendo, pela afirmação de Guimarães Rosa, da existência desse lugar em suspensão que não é materializado no livro como uma presença, não temos acesso a ele. Dele só sabemos, paradoxalmente, de dentro, a partir de cada livro escrito, no qual e ainda nele tudo recomeça, como nos esclarece Derrida: "Diz-se a saída para fora do livro, diz-se o outro e o limiar no livro. O outro e o limiar só podem escrever-se, confessar-se ainda nele". (DERRIDA, 1995, p. 69). Na verdade, ao rondar o fora do livro, tal como as variações das imagens em trânsito das provas de estado, encontrei-me andarilhando por regiões incertas, em que é possível permanecer dentro e fora ao mesmo tempo, em "uma caminhada nas regiões fronteiriças e na fronteira da caminhada”. (BLANCHOT, 2001, p.64).

Permanecer no limiar permite àquele que escreve tomar o livro como objeto ambíguo, presente e ausente dele mesmo e de suas margens, como o fez Guimarães Rosa no prefácio “Aletria e Hermenêutica”, e de poder contestá-lo, negando-o como espaço finito capaz de circunscrever a palavra escrita. Negar a finitude da escrita no livro encarna a experiência de muitos escritores. Como, por exemplo, Joseph Joubert: autor sem livro, escritor sem escrito que dedicou toda sua vida preparando um livro que queria escrever, esquecendo-se ao final de seu propósito; ou Jorge Luis Borges, em "O livro de areia”, no qual várias folhas se interpunham entre a portada e a mão do leitor como se brotassem do livro, impedindo que se numerasse a primeira e a última página; ou Rosa em "Tutaméia", ao nos convidar para fazermos juntos um certo livro, em que "tudo nem estava concluído, nunca, êrro, recomeço, reêrro. (ROSA, 1985, p. 165); ou Edmond Jabès em "Le livre des quéstions" em que se coloca diante do livro escrito, não como o guarda da casa, mas como 
aquele que permanece à porta, no limiar, ou ainda Waltércio Caldas em "O livro carbono", objeto que, impresso, não para de se imprimir e de se reimprimir.

O que esses escritores buscam, na verdade, é resgatar o que se separa na passagem do manuscrito ao impresso, o que do livro foi subtraído: a experiência da escrita, as rasuras, a desordem da escrita, o movimento das palavras que nenhum livro é capaz de abrigar. Recuperar no livro o espaço flutuante das margens significa, para eles, sobretudo o desejo de deixar latente no livro, para além de sua concretude de objeto, os estados do livro, evitando assim, preencher um momento único e irremediavelmente fugidio da escrita, cientes que, do ponto de vista material, o livro impõe à escrita seus limites.

Em torno desses escritores se reúnem, ainda, por afinidades eletivas, segundo Augusta Babo (1993), autores para os quais a escrita des(cons)trói os limites do livro. São eles: Derrida acerca de Jabés, Blanchot acerca de Mallarmé, Roger Laporte acerca de Joubert. Em cada um desses pares, o comentário é exercido por sujeitos que experimentam eles próprios essa vertigem da repetição, da ausência de qualquer origem, da emergência da escrita à margem ou no fim do livro, tal como formula Laporte, referindo-se aos seus próprios livros: "Como fazer de tal maneira que escrever seja, ao mesmo tempo, o sujeito e o objeto, o conteúdo, o núcleo e a matéria de um livro em que o branco, longe de estar localizado e mantido à margem, se dissemine por toda a página?" (BABO, 1993, p. 61).

Na tentativa de apagar esses limites, a experiência a que esses escritores se entregam já não é mais a da escrita do livro, mas, sim, a de como inscrever a escrita no livro, de tal modo que o que dele foi subtraído nele seja inserido, acrescido de suas margens. E de lá, junto com Rosa e muitos outros, fazer emergir do livro também o seu outro, além e ou aquém dele mesmo, em infinito movimento.

Para dar visibilidade ao livro como um espaço de coexistência dos contrários, que ora abriga, ora desabriga a palavra escrita, autores como Derrida e Compagnon vão questionar exatamente a geografia de suas margens, os elementos paratextuais que o constroem como objeto, sobretudo o estatuto do prefácio. Questionam a palavra primeira dirigida ao leitor, mas que, paradoxalmente, é aquela que se escreve por último, a que fecha o livro, e que marca, nas palavras de Compagnon, um lugar de despossessão para que o livro entre em um outro universo, o da publicação: "está findo aqui o sujeito que fui, enquanto escrevi isso que você vai ler” (COMPANGNON, 1996, p. 87).

Desconstruir os limites do livro significa, então, adiar essa despedida, confundir a palavra final com a primeira fazendo com que elas se reenviem uma à outra, desestabilizando, assim, a função paratextual do prefácio, que determinará apenas o fim do livro e não o fim da escrita.

Deparamo-nos, assim, com a mesma afirmação paradoxal em relação ao espaço da escrita no livro: para Compagnon, o começo do livro é o fim da escrita, enquanto para Derrida, o fim do livro é o começo da escrita. Uma desordem se instaura e o livro torna-se objeto de passagem da escrita, pois abrigar a última palavra é, também, abrigar a seguinte. Afinal, aquele que termina um livro já começa outro e desejaria sempre acrescentar algo mais, não terminar nunca, fazendo com que ele se torne "a «sua própria reserva〉, uma virtualidade inesgotável que impede de dar fim à escrita”. (BABO, 1993, p. 65). 
Estamos no livro como em um círculo da imensidade, e tal como Joubert, sob a miragem fascinante do movimento das palavras:

Acrescentai o círculo da imensidade!

(...) Acabar! Que palavra! Não acabamos quando paramos, ou quando declaramos ter terminado.

Minhas ideias!

É a casa para abrigá-las que me custa a construir.

(JOUBERT apud BLANCHOT, 2005, p. 77)

Esse pensamento move meus estudos sobre o estatuto da escrita, da imagem e do livro, e é ainda ele que constrói a "Biblioteca Para-Luz" e seus desdobramentos, pesquisa que venho desenvolvendo desde 2009. Uma ficção do livro no mundo do livro, que se organiza por um caminho inverso. Ela subverte a ordem dos livros e cria primeiro aquilo que deveria ser feito por último, as suas margens, ou seja, as capas com lombadas impressas, pequenas marcas d'água, fitas, etiquetas de uma catalogação flutuante e títulos provisórios esvoaçantes, como que possibilitando transitar de um livro para o outro de tal modo que o título de um poderia, poderá ser de outro. Nessa biblioteca, nada mais a medir, a fixar, é como se ela estivesse suspensa no tempo e no espaço, invólucros vazios de um instante em instância, de passagem da escrita que já se foi e da escrita que ainda não chegou. Ela encarna, também, a mesma dificuldade de Joubert em construir uma casa para abrigar suas ideias, e que talvez ele encontrasse na topografia irregular da casa construída pela personagem de Rosa, um século mais tarde, no conto "Curtamão": "de costas para o rual, respeitando frente a horizonte e várzeas", em "infinito movimento sem a festa da cumeeira". (ROSA, 1985, p. 36). 

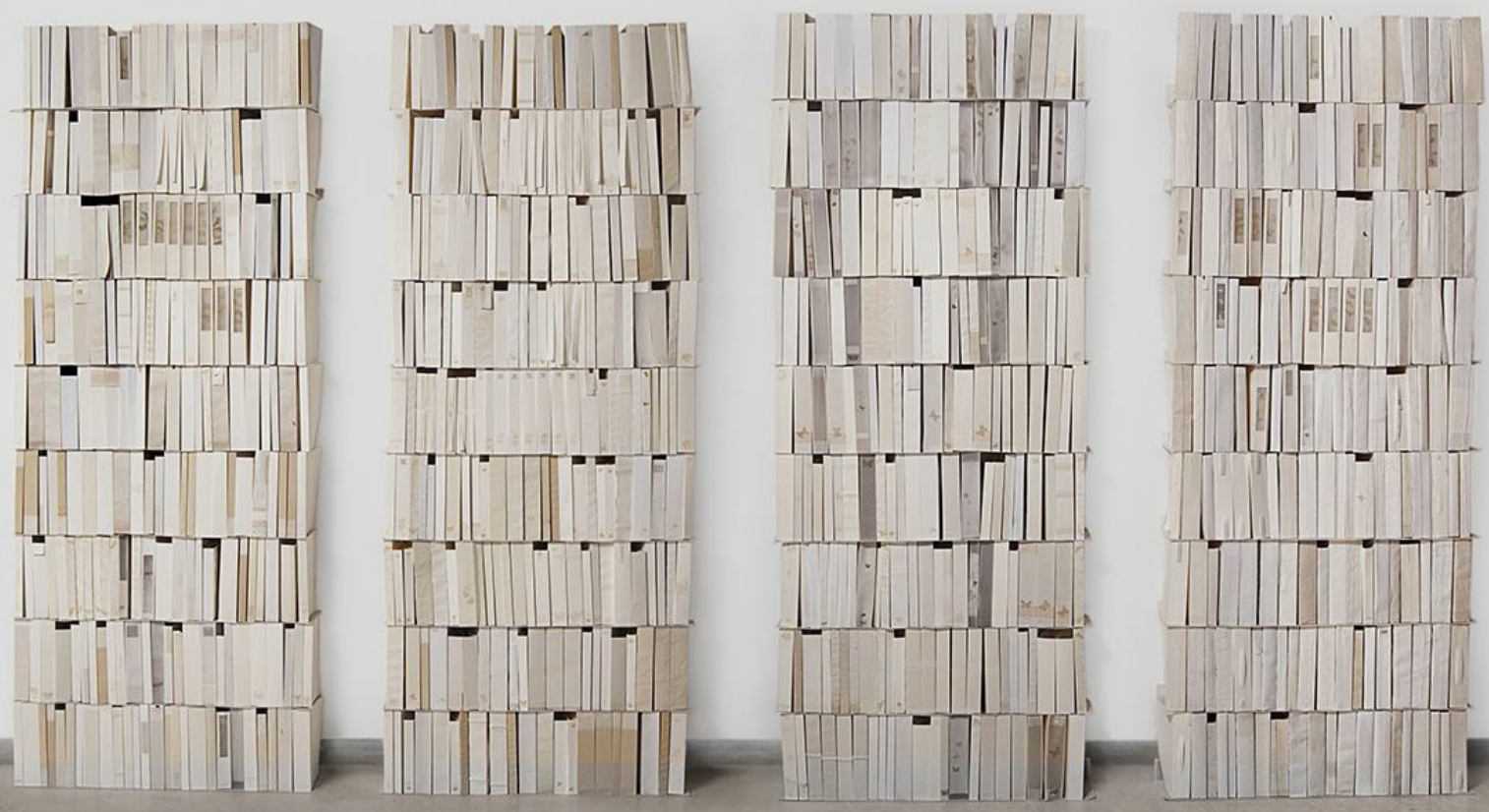

Figura 1 - Daisy Turrer, “Biblioteca Para-luz”. Instalação realizada no Espaço Cultural FIEMG, em Ouro Preto/ MG, 2009. Fotografia: Miguel Aún.

"Para-Luz" constrói-se, também, por uma topografia irregular, feita de inacabamentos, de tudo que cerca a gravura: papel jornal, papel de seda, papel carbono, talagarça, provas de estado, registros deslocados de gravuras que não foram editadas, das experiências inesgotáveis das impressões e de papéis amarelados e fungados que o tempo gravou e transformou. $E$ ainda pelos para-sóis, objetos feitos de improviso, com pedaços de papel manteiga e molduras velhas para registrar a escrita de luz e sombra de seus livros insones, sem pouso no presente, pois o que eles registram e neles estão grafados são apenas traços indecisos da sombra que já se foi. 


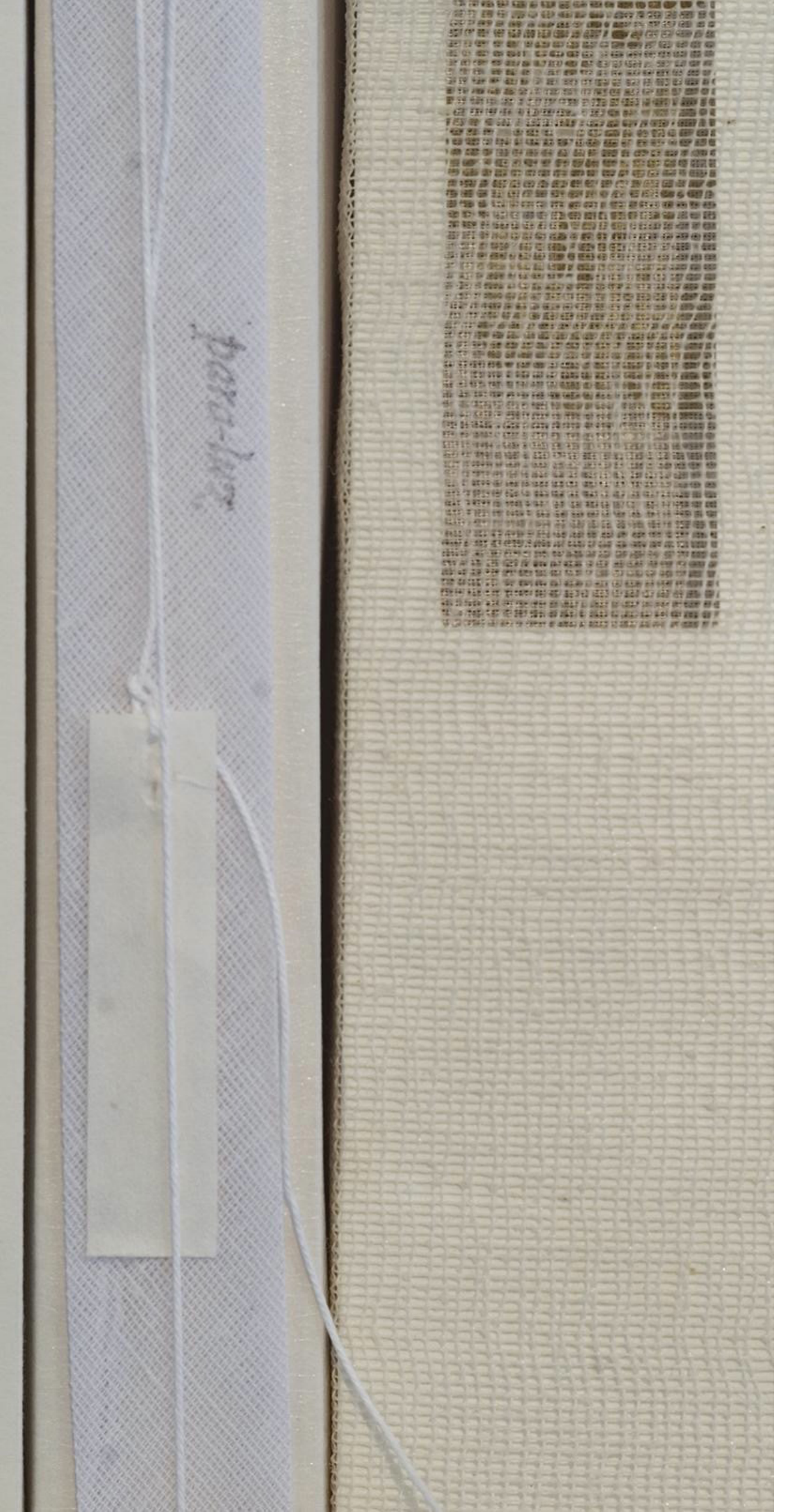




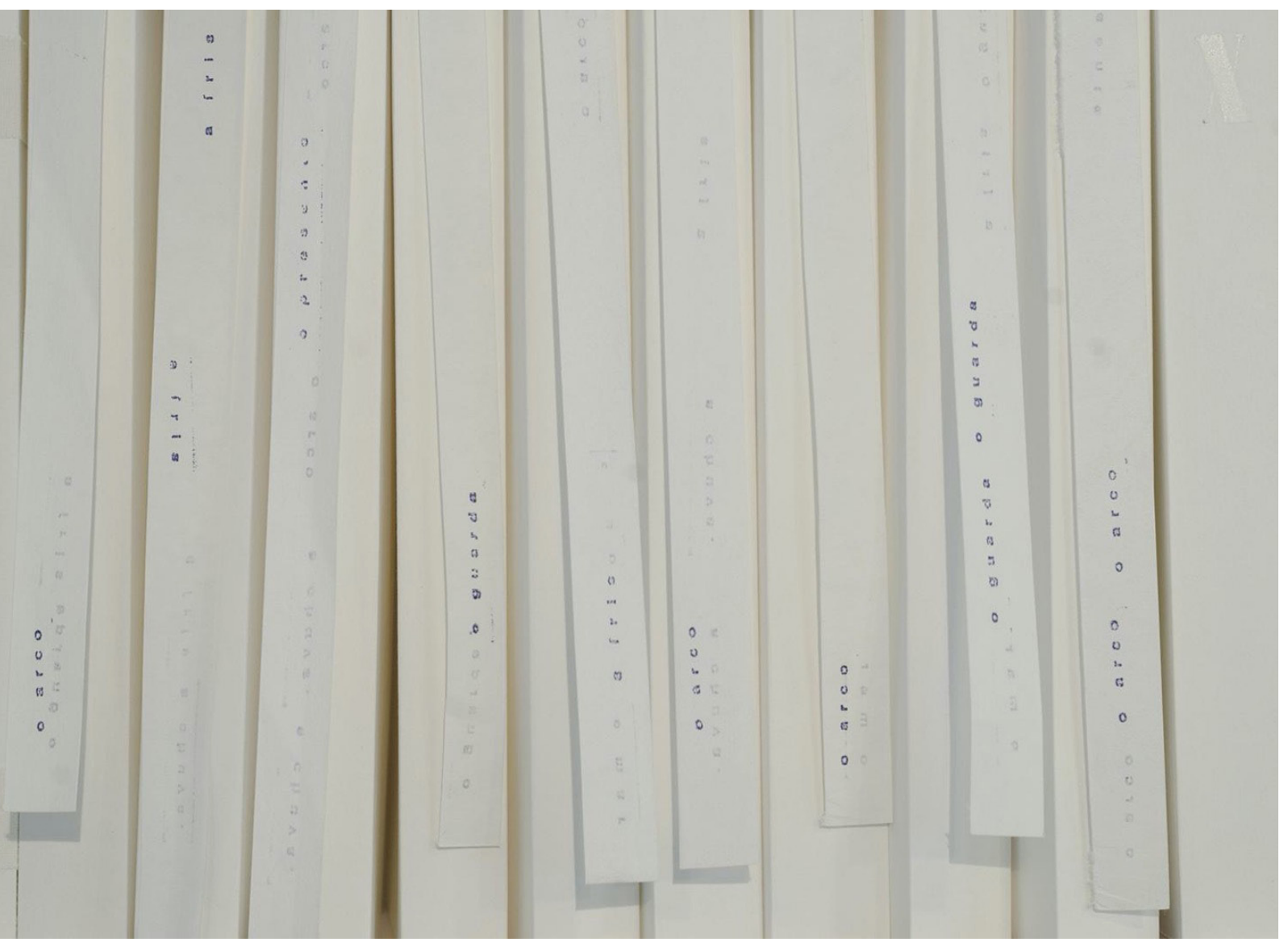

Figuras 2 (página anterior) e 3 (acima) - Daisy Turrer, "Biblioteca Para-luz" (detalhes). Instalação realizada no Espaço Cultural FIEMG, em Ouro Preto/MG, 2009. Fotografia: André Hauk.

Figura 4 (p’róxima página) - Daisy Turrer, “Tirar o risco: decalques da Biblioteca Para-luz”, 2017. Fotografia: Margarida Campos. 
O presente também falta aos livros dessa biblioteca, como na frase de Blanchot citada na epígrafe: "Para escrever é preciso que já se escreva" (BLANCHOT, 1987, p. 176). Falta o livro amarrado e costurado, o livro como presença, e o que ela nos apresenta são livros à espera do que está para se escrever ou, ainda, do que escrito dele foi subtraído, e que só se faz ler no espaço e no tempo sem fim do imaginário através de seus vestígios: pequenas estampas de carimbos e clichês, de livros encapados semi-velados e reaproveitados em outras coleções, de papéis empilhados sobre as mesas, de pranchas avulsas de desenhos e decalques de sombras rebatidas, de pequenos para-sóis de mesa, de páginas de panos impressos entintados por águastintas de anil, dobrados, redobrados, alvejados e de livros avulsos em diferentes espessuras e formatos, além de livros-caixas, depositários de pó de grafite, de recortes e de etiquetas. Estes, documentam as "janelas de prospecção" deixadas em um fragmento de parede nos museus e casas restauradas, como uma página retirada de um livro polvilhado de cal e respingos de cores colhidas do tempo que já se foi e do qual só podemos imaginar e oscilar entre o que teria sido e o que no agora ele veio a ser. 


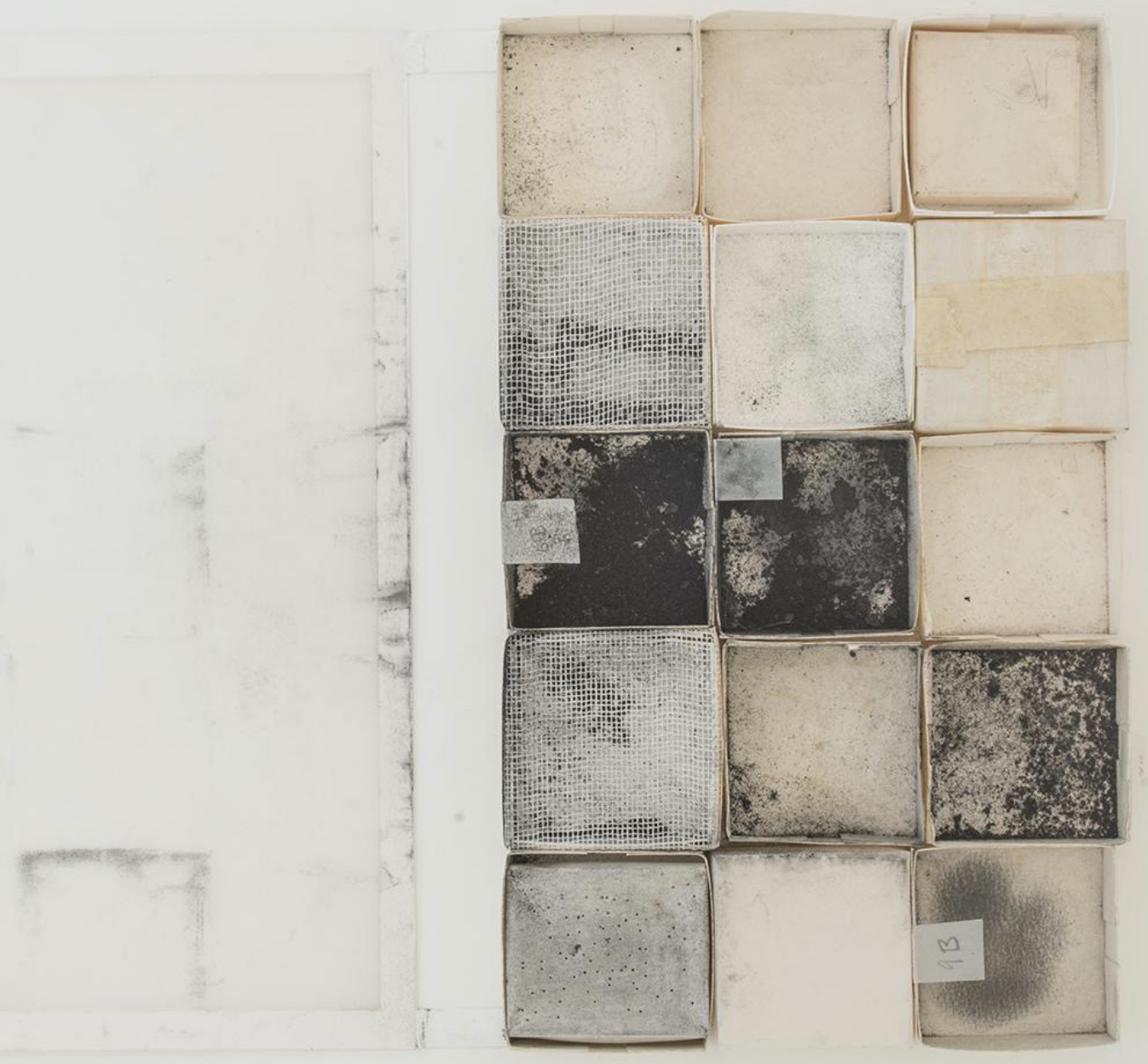

Figura 5 - Daisy Turrer, “Livro II: das sombras”, 2017. Fotografia: Ícaro Moreno.

Figuras 6 e 7 - Daisy Turrer, “Janelas de prospecção (detalhes), instalação realizada no Museu Mineiro, em Belo Horizonte, 2019. Estadia 2, do grupo Grassar: ações continuadas em arte da Escola de Belas Artes da UFMG. Fotografias: Ícaro Moreno. 

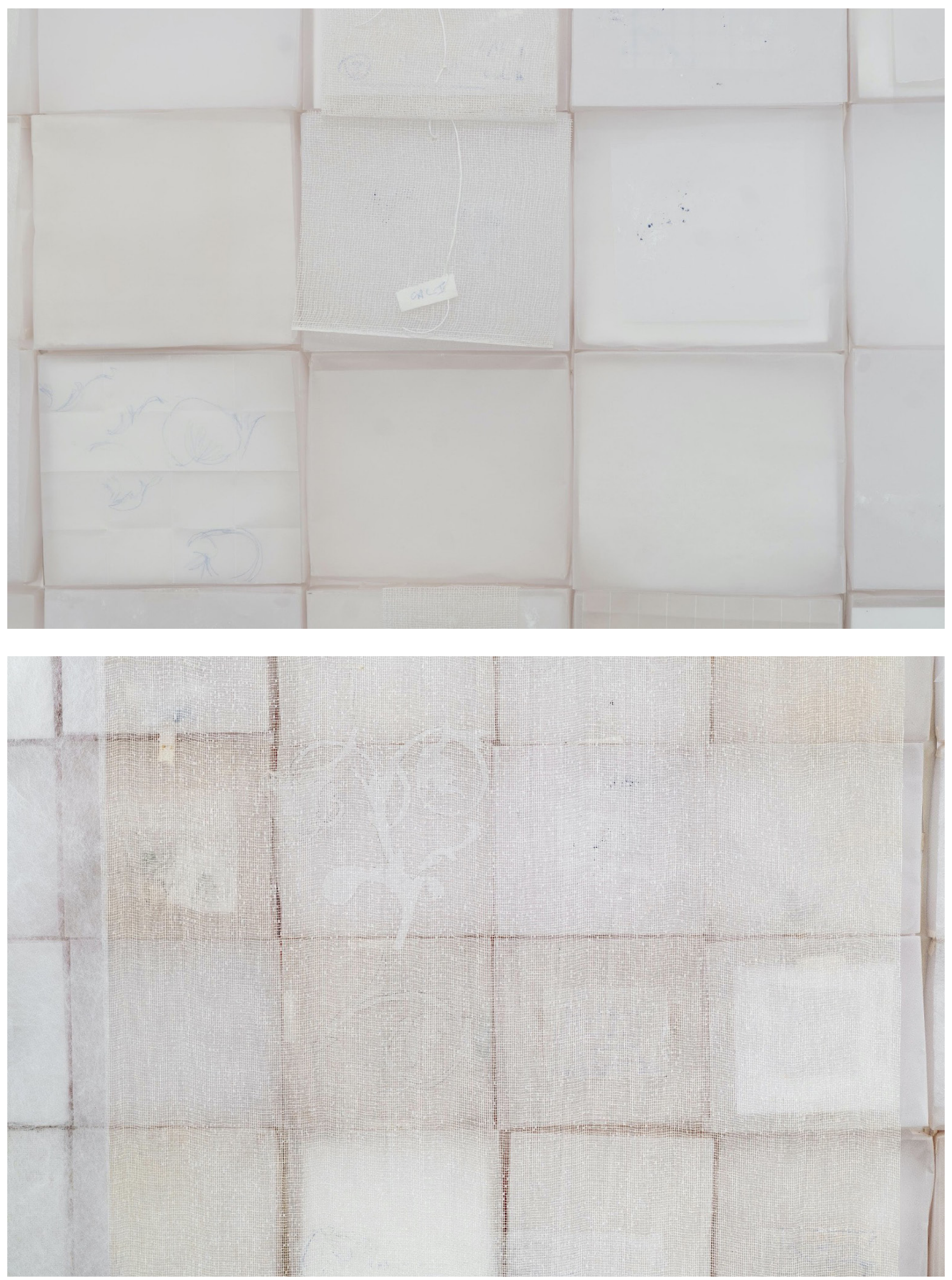
Os livros vazios da estante e os que se espalham sobre as mesas e vitrines jamais são costurados e amarrados, como que para garantir o poder de escrevê-los e reescrevê-los, de acrescentar ou retirar páginas. Eles se equilibram em estantes cujas prateleiras são feitas de papel, sempre prontos a serem desmontados, dobrados e catalogados de forma diferente, e, sobretudo, para que possam mudar a ordem dos livros que variam a cada montagem, sempre acrescidos e ou subtraídos de algo, de acordo com a luz filtrada das janelas, ou das luzes do espaço expositivo.

São livros que saem dos livros e voltam para os livros, páginas soltas que viajam e são capazes de pousar sobre qualquer suporte como no livro "Da lonjura", instalação realizada no Museu da Inconfidência em Ouro Preto ${ }^{3}$. Nesse trabalho, a "Biblioteca Para-luz" se desloca para a sala do panteão para transformar as lápides de Thomás Gonzaga e de Marília de Dirceu em livros, páginas do que se escreveu no passado com palavras endereçadas ao futuro:

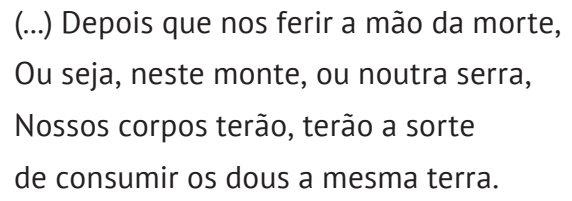

(GONZAGA, 1997, p. 83).

Em salas diferentes no museu e entrevistos aos visitantes apenas por um desencontro de paredes, eles se encontram, agora, entre as pilhas de papéis da "Biblioteca Para-Luz", no limiar do livro, entre a capa e o texto, na folha de rosto na qual está impresso o verso do poeta. Página que o fecha, mas que, também, o abre para o livro seguinte, que o Museu da Inconfidência abrigou temporariamente e compartilhou com seus leitores à sombra de letras de um ramo de cedro e um galho de candeia.

Figuras 8 e 9 (página seguinte) - Daisy Turrer, "Da lonjura” (detalhe). Site-specific realizado no Museu da Inconfidência de Ouro Preto/MG. Estadia 1, do grupo Grassar: ações continuadas em arte da Escola de Belas Artes da UFMG. Fotografias: Alexandre Rezende.

3 Da lonjura foi apresentado na exposição coletiva Estadia 1, do grupo Grassar: ações continuadas em arte da Escola de Belas Artes da UFMG. 


\section{का}


Joubert, em suas noites insones a mirar as estrelas no céu, descobre que na literatura todas as coisas se dizem, se mostram e se revelam, verdadeiramente, assim que se distanciam e se espaçam para, finalmente, se atenuarem e se expandirem no vazio incircunscrito e indeterminado que só a imaginação nos oferece, concluindo com ousadia que "esse vazio e essa ausência são o próprio fundo das realidades mais materiais, a tal ponto que, diz ele, se espremêssemos o mundo para fazer sair dele o vazio ele não encheria nossa mão". (BLANCHOT, 2005, p. 81).

Podemos pensar o mundo espremido de seus vazios como um livro, objeto que caberia em nossas mãos e a ele nos afeiçoamos, mas também como o livro expandido, indefinido, que possa ser lido no vazio cheio do mundo, sem princípio nem fim. Este já não poderia ser reproduzido em um livro, pois perderia, nas palavras de Blanchot, todo o fim e "não seria mais o mundo, seria, será o mundo pervertido na soma de seus possíveis" (BLANCHOT, 2005, p. 140). As palavras "seriam, será" trazem com elas o indefinido e é ele, para o autor, "a essência do imaginário", o que sempre impede K. de chegar ao Castelo, assim como impede, por toda a eternidade, que Aquiles alcance a tartaruga" (BLANCHOT, 2005, p. 140), e que impede, sob o ponto de vista dos autores aqui reunidos, que a escrita de um livro termine no livro.

Estamos diante de um certo livro, aquele que Guimarães Rosa nos convida a fazer juntos em "Tutaméia”, em que tudo nem estava concluído, como escreviam Aquiles, Bindóia, o próprio Manuelzão. lam, "nômades de monotonia", citando alto, enquanto não lidavam ou aboiavam, cada coisa avistada, cada pormenor - "ave e vôo, nuvem, morro, riacho, poeira, pau-de-flor, ou nada toadamente" (ROSA, 1985, p. 180). A “Biblioteca Para-Luz", movente e indefinida, recolhe passagens da escrita no descampado do vazio cheio do mundo, imagens de uma tipografia improvável, organizada toadamente, de livros avistados e... a avistar.

\section{REFERÊNCIAS}

BABO, M. A. A escrita do livro. Lisboa: Vega, 1993.

BLANCHOT, M. O espaço literário. Trad. Álvaro Cabral. Rio de Janeiro: Rocco, 1987.

BLANCHOT, M. 0 livro por vir. Trad. Leyla Perrone Moisés. São Paulo: Martins Fontes, 2005.

BORGES, J. L. 0 livro de areia. Trad. David Arregucci Jr. Sâo Paulo: Cia as Letras, 2009.

COMPAGNON, A. 0 trabalho da citação. Trad. Cleonice P.B Mourão. Belo Horizonte: Editora UFMG, 1996. 
DERRIDA, J. A escritura e a diferença. Trad. Maria Beatriz Marques Nizza da Silva. 2ed. São Paulo: Perspectiva, 1995.

GONZAGA, T. A. Marília de Dirceu e Cartas Chilenas. São Paulo: Ática, 1997.

ROSA, João Guimarães. Tutaméia: terceiras estórias. Rio de Janeiro: Nova Fronteira, 1985.

SALTZSEIN, S. Livros. Catálogo da exposição Museu de Arte da Pampulha. Belo Horizonte, 2000.

TURRER, D. L. 0 livro e a ausência de livro em Tutaméia de Guimarães Rosa. Belo Horizonte: Autêntica, 2002.

TURRER, D. L. O livro de artista e o paratexto. In: Pós: Revista do Programa de Pós Graduação em Artes, v.2, n.3, Belo Horizonte: Universidade Federal de Minas Gerais, 2012, p. 73-81.

\section{Sobre a autora}

Daisy Leite Turrer é artista, pesquisadora e professora. Doutora em Literatura Comparada e mestre em Estudos Literários pela Faculdade de Letras/ UFMG. Professora aposentada de Gravura do Departamento de Artes Plásticas e do Programa de Pós-Graduação em Artes da Escola de Belas Artes da Universidade Federal de Minas Gerais. Fundou e coordenou o Núcleo de Estudos da Cultura do Impresso NECI-EBA (1997-2007). Participou de bienais de gravura no âmbito nacional e internacional e tem participado de várias exposições. Dedica-se, atualmente aos estudos sobre a imagem a escrita e o livro e às pesquisas sobre os desdobramentos da gravura em instalações, fotografias, objetos e edições.

Lattes: http://lattes.cnpq.br/2289996597095026

Orcid: https://orcid.org/0000-0003-2083-4638

Recebido em: 16-10-2020 / Aprovado em: 30-10-2020

\section{Como Citar}

TURRER, D. L. (2020). Livro: círculo da imensidade. Revista Estado da Arte, Uberlândia. v.1, n.2, p.59-73, jul./dez. 2020. https://doi.org/10.14393/EdA-v1-n2-2020-57779W 